\title{
CARDIOSPASM
}

\author{
By A. S. Johnstone. M.D., F.R.C.S.(ED.), F.F.R. and G. H. Wooler, M.A., M.D., F.R.C.S. \\ From the Leeds General Infirmary
}

The number of synonyms - achalasia, oesophagectasia, idiopathic dilatation; mega-oesophagus, neuropathic dilatation, phrenospasm-is in itself an indication of the wide diversity of opinions regarding the cause of this disease. The term cardiospasm is used here because the writers believe that spasm exists in the majority of patients. Cardiospasm, however, is not an isolated lesion of the cardia but is part of a disordered mechanism of the whole oesophagus, to be described later.

\section{Anatomy and Movements of the Oesophagus}

The oesophagus is divided into two segments. The upper segment comprises the proximal third lying above the aortic arch. Its wall is composed of striped muscle supplied by the recurrent laryngeal nerves. The lower segment comprises the distal two-thirds lying below the aorta ; its wall is of plain muscle supplied by the vagal plexus. The nerve fibres supplying these two segments of the oesophagus originate from different nuclei in the medulla, and control the movements of the oesophagus which are different in the two segments.

There are three forms of oesophageal contractions : primary, secondary and tertiary. The primary wave is initiated by the act of swallowing ; it begins in the upper third of the oesophagus and proceeds in an unbroken manner down to the cardia. As it passes downwards, the oesophagus above the advancing wave remains in a state of contraction. Von Brücke and Satake (1913), studying oesophageal action currents, concluded that the primary wave was an advancing tetanic contraction (Fig. I).

The secondary wave originates in the region of the aortic arch, and is confined to the plain muscle segment. It is initiated by the presence of food in this part of oesophagus and is of a similar nature to the primary wave, consisting of a band of contraction passing down to the cardid. McLaren (1943) showed by kymography that these waves were not preceded by waves of relaxation and so were not the same as true peristalsis in other parts of the intestinal canal.
Tertiary waves also arise in the plain muscle segment. They are small worm-like contractions occurring when the oesophagus is distended, lasting only a moment and, if there are many of them, the oesophagus has a serrated appearance. They are due to rings of contraction in the circular muscle of the oesophagus (Fig. 2).

Reversed peristalsis has also been described as occurring in the lower segment of the oesophagus. This is probably not true, for a wave of contraction passing down to the cardia naturally raises the level of retained barium if the fluid is unable to pass through into the stomach. Thus the barium oscillating up and down the oesophagus gives this impression of reversed peristalsis.

\section{Aetiology}

The aetiology of the condition remains unknown and there are probably several factors contributing to the onset of the disease. By far the most important is psychogenic trauma. Psychiatrists contend that infants develop complexes soon after birth; there would therefore appear to be no reason why cardiospasm should not occur at this early age following psychogenic trauma. Our youngest patient was a baby girl who commenced to vomit when she was weaned at nine months. She was an only child, and even at this early age was obviously nervous and highly-strung.

There is no doubt that a strong psychological background is present when cardiospasm occurs in adolescence or in later life. In such a case, the cardia appears to be governed by emotion, and goes into spasm with excitement.

In this series of $6 \mathrm{I}$ cases two psychological types are evident :-

I. The highly-strung nervous individual who looks thyrotoxic.

2. The quiet, introspective type.

There is some evidence to support the hypothesis that in the early stages of this disease the behaviour of the oesophagus, as seen radiologically, differs in the two types. In the first, vigorous contractions can be observed; in the second, the oesophagus is passive and inert.

Dr. Soler Roig of Barcelona, in a personal 
communication, stressed the importance of psychotherapy in cardiospasm. The disease is extremely common in Spain, and many of his patients are cured by this therapy alone. Such results have not been obtained in Great Britain. In our experience the lesion appears to be organic and is not cured by psychotherapy.

Allison has had two cases of cardiospasm occurring in old age after cerebral vascular lesions. It therefore seems probable that there is a centre in the brain controlling the movements of the oesophagus and the tone of the cardiac sphincter.

Example. A woman, aged 62, suffering from polycythaemia vera developed a severe headache and weakness of her left leg. At the same time, she noticed that she was unable to swallow. Radiologically and at oesophagoscopy, she showed the typical appearances of cardiospasm. Her dysphagia was relieved by treatment with the Negus hydrostatic dilator.

No case in this series was associated with other neuro-muscular disorders such as magacolon. One had duodenal ileus and two had gastric ulcers. These were thought to be incidental findings in no way connected with the disease.

A condition similar to cardiospasm sometimes occurs following vagotomy. Rob demonstrated this complication in 1947 , since when we have seen two cases. The dysphagia is of a transient nature, coming on about three days after vagotomy and lasting for a week or. so before it gradually disappears. Radiologically, there is a constriction at the lower end of the oesophagus in the region of the cardia. Proximal to the constriction the oesophagus is dilated and inactive. There appears to be no increased activity to overcome the constriction.

\section{Age and Sex Incidence}

Cardiospasm affects people of any age. The youngest of the patients reviewed in this paper commenced to vomit when she was nine months old; the oldest was 73. The usual age for the disease to manifest itself is during the third decade. In this series it occurred twice as commonly in women as in men.

\section{Clinical Features}

Cardiospasm gradually alters the mechanism of the whole oesophagus. In the untreated case, the disease may appear to fluctuate and swallowing to improve at times, but radiologically and in fact the disease runs a continuous, slow, progressive course which may be divided into two stages. The first is of greatly increased activity of the oesophagus ; the second is the gradual cessation of all activity followed by passive dilatation.
First stage. Patients in the first stage are $\stackrel{\overrightarrow{0}}{7}$ 'oesophagus-conscious.' They can feel the cardia go into spasm when they are excited and can feel 3 it relax after a hot drink. The first few mouthfuls $\stackrel{\varnothing}{\varrho}$ of food may cause little discomfort, but further $c$. swallowing produces the sensation that food is $\overrightarrow{\vec{F}}$ sticking behind the lower third of the sternum. If they continue to eat rapidly, food regurgitates? into the pharynx. These symptoms may fluctuate $\frac{\overline{\bar{D}}}{\bar{\rho}}$ from day to day, but on the whole they gradually $\vec{\nabla}$ worsen as the disease progresses. Any un- $\varrho$ toward incident may bring on an attack. It is of $\%$ interest to note that the patients who had not been $\overrightarrow{0}$ relieved completely by treatment felt very much worse when they received a letter asking them to $\vec{\omega}$ report again to hospital for review.

Three of the patients in this series complained $\stackrel{0}{7}$ that food stuck in the throat, just above the level of the jugular notch. Two of the three also com- $N$ plained that food stuck behind the lower sternum. N This sensation of food sticking in the throat with the obstruction at the cardia sometimes occurs in $\mathrm{C}^{-}$ cases of carcinoma of the cardia.

The stage of activity just described lasts for ${ }^{\circ}$ months. The oesophagus then tires of its in- $\vec{z}$ creased effort and becomes passively dilated. The second stage is now reached when most patients $\vec{\varphi}$ present themselves for treatment.

Second stage. During the second stage. dysphagia and sternal discomfort after swallowi grow in severity. Patients try to combat the symptoms by eating slowly, choosing their dieto carefully, and washing solids down with fluids, $\stackrel{\varrho}{\circ}$ but they lose weight rapidly because they cannot $\stackrel{\square}{\complement}$ swallow sufficient food. If the cricopharyngeus is $\overrightarrow{\overrightarrow{0}}$ not functioning properly, they complain of re- 3 gurgitation of food into the mouth at night, and of choking. They become thin and anaemic ando may present in a severe degree of cachexia.

\section{Complications}

Cardiospasm sometimes causes certain complications which may be the presenting symptoms. In this series of 61 patients, three presented with lung complications and two with rheumatism.

\section{Lung Complications}

I. Atelectasis. A girl, aged 16, gave a two N months' history of cough with sputum, dyspnoea and two haemoptyses. Radiography showed collapse of the right lung caused by pressure on thew right main bronchus. It was only after close questioning that a history of dysphagia could beo obtained. This had developed at the age of ten, when she was too young to appreciate her con-? dition. Her mother thought that she had merely gone off her food. During the subsequent five years, the oesophagus gradually dilated, eventually 
compressing the right main bronchus. Enlargement of the oesophagus to the left was prevented by the aortic arch and the descending aorta (Fig. 4).

2. Pneumonitis and bronchiectasis. A girl of 18 presented as a typical case of bronchiectasis. She gave a history of pneumonia five years previously, and as a result she developed a cough which had persisted. Attacks of bronchitis had recurred each winter, and one week before her first attendance she had a small haemoptysis. She gave no history of dysphagia ; there was nothing in her symptoms to suggest that she had cardiospasm. Her chest radiographs, however, showed cardiospasm and bilateral bronchiectasis, which was probably due to a chronic inhalation pneumonia, caused by food which had regurgitated from the oesophagus (Fig. 5). Belcher (1949) has recently described similar pulmonary complications.

3. Paraffin pneumonia. The third lung complication occurred in a woman aged 31 , who had been in the habit of taking liquid paraffin after every meal because she believed that it ' lubricated her alimentary tract,' allowing food to glide into ihe stomach. The paraffin, being of low density' floated on the top of the liquid content of her oesophagus. She also found eating such a nervous strain that she had to lie down after every meal. Small amounts of liquid paraffin then regurgitated into her pharynx, which she inhaled, causing a paraffin pneumonia (Fig. 6).

\section{Rheumatic Complications}

I. Toxic arthritis. A woman, aged 42, stated that her joints had been swollen for two months, the interphalangeal, knee- and elbow-joints being most affected. When questioned she gave a ${\mathbf{~} 5^{-}}^{-}$ year history of dysphagia which commenced after her first pregnancy. She had an enormously dilated oesophagus, the contents of which smelt as bad as a pelvic abscess. The lower third of the oesophagus was found to be grossly inflamed and ulcerated.

The arthritic condition was probably due to toxic absorption from the ulcerated oesophagus, for after the oesophagus had been washed out and the cardiospasm relieved by dilatation, her joint symptoms dramatically cleared up overnight. The relief, however, was only temporary, and when the spasm returned, her joints swelled up again. The . patient, in fact, was able to tell the condition of her cardia merely by inspecting her joints.

2. Rheumatoid arthritis. A woman, aged 32, presented as a case of rheumatoid arthritis with swelling of her hands, knees and elbows. The condition of her joints cleared up just as effectively as in the previous patient after the cardiospasm had been relieved.

\section{Relation to Carcinoma}

Carcinoma is a very rare complication of cardiospasm but has been found arising in the dilated oesophageal wall. Much more frequently, however, carcinoma arises in the fundus of the stomach or the lower end of the oesophagus and produces oesophageal dilatation which radiologically may be mistaken for cardiospasm.

\section{Diagnosis}

The diagnosis is usually established by radiology. Oesophagoscopy should be carried out in all cases to confirm the diagnosis and also for the introduction of therapeutic measures.

\section{Radiological Findings}

First stage. Fluid barium is held up in the oesophagus by a spasm affecting the diaphragmatic portion. This segment is narrow but smooth, and has a beak-like appearance. Between the aortic arch and the diaphragm the lumen is widened but the change occurs gradually. The walls are serrated by the tertiary contractions, which may be vigorous and cause repeated changes of contour. Above the aortic arch one may find the greatest dilatation, but the lumen is normal in the postcricoid segment and the upper sphincter prevents regurgitation (Fig. 8a and b). As previously mentioned, there are vigorous irregular waves which sometimes cause a writhing movement in the oesophagus. Normal peristalsis is absent. The tertiary contractions in the plain muscle segment which replace the ordinary primary and secondary waves are most striking and are in most cases diagnostic.

Second stage. When the tertiary contractions lessen, dilatation of all except the diaphragmatic portion occurs. A straight film of the chest may show :-

(a) An opacity emerging from the superior mediastinum, spreading over and obscuring the right hilum to disappear behind the right border of the heart (Fig. 4).

(b) Rounded opacities which may appear over the right hilum, in the right cardio-phrenic angle and, in films of more penetration, through the cardiac shadow to the left of the spine. Associated with these opacities there may be signs of lower lobe atelectasis, bronchiectasis or the mottling of inhalation pneumonia.

(c) In the oblique views there is loss of the clear posterior mediastinal space, and a fluid level may be seen adjacent to the aortic arch.

A drink of barium immediately demonstrates the dilated oesophagus, and the opaque medium drops slowly through the collection of food and 
fluid. It usually sinks down the left anterior part of the sac and collects at the bottom, demonstrating the smooth convex walls, which narrow suddenly at the diaphragm to produce a beak-like channel through which the barium passes intermittently, often in spurts, into the stomach (Fig. 3).

As full inspiration takes place, the beak appears at first to be lengthened and then obliterated; with expiration the relaxation of the diaphragmatic hiatus allows the beak to widen and a narrow stream of barium may pass through. The effect of this action of the diaphragm on the lower end of the oesophagus may be described as 'milking.' The pliability of the walls of the dilated portion indicates that they are probably not infiltrated and this observation may be helpful in excluding a neoplasm (Fig. 9a and b).

The inhalation of octyl nitrite may, within a few seconds, produce some relaxation, but this is not a frequent finding. A glass of hot water flushes the oesophagus most effectively, and the barium is quickly evacuated leaving the food contents behind.

Absence of air in the fundus of the stomach is a regular feature. In consequence it may be difficult to obtain a clear view of the mucosa and thickness of the gastric wall, so that the exclusion of a fundal neoplasm may be impossible.

\section{Oesophagoscopy}

If the barium swallow shows the oesophagus to be dilated, oesophagoscopy is more safely performed with local anaesthesia. Under general anaesthesia, when the cough reflex is abolished, food regurgitating into the pharynx may quickly be inhaled. It is absolutely essential to avoid this. If the oesophagus is greatly dilated, it may contain foul-smelling fluid due to bacterial decomposition. The oesophageal mucosa may be inflamed and show gross ulceration, which is in part due to stagnation and decomposition of its contents, and in part due to pressure necrosis caused by the weight of retained food in the lumen. It is the lower horizontal part of the oesophagus running behind the heart to the hiatus which bears the full weight of the contents, and is consequently the first to ulcerate. In this series of $6 \mathrm{I}$ cases, three showed gross ulceration.

After the oesophagus has been cleansed, the cardia may be difficult to find, for the adult Negus oesophagoscope will not reach to the cardia of a greatly lengthened and kinked oesophagus. It lies around a bed to the left (Fig. II). When, however, the cardia has been found it appears rather like the top of a purse with folds of mucosa radiating from the centre of it. A fine bougie passed through it is gripped sufficiently to cause a slight resistance. It is definitely gripped, but it is not a tight constriction.

After dilatation of the cardia, stomach contents regurgitate back into the oesophagus. Frequently $\underset{\propto}{\otimes}$ the junction of oesophageal and gastric mucosa can $\frac{\Omega}{c}$ be seen. Allison, using his clip method, applied $\mathrm{a} \rightleftharpoons$ Cushing clip to the junction of the two mucosae. In a few cases it was subsequently shown that this clip was lying at the proximal end of the oeso- $\frac{\bar{O}}{\bar{F}}$ phageal constriction. In certain cases, therefore, $\frac{\bar{\omega}}{\vec{Q}}$ the part actually in spasm is lined by gastric mucosa. $\stackrel{\mathbb{2}}{\triangle}$

\section{Differential Diagnosis}

Carcinoma. Early carcinomatous infiltration, $\vec{\circ}$ particularly an adenocarcinoma arising in the $\vec{\omega}$ cardiac antrum, may produce changes so similar to cardiospasm that radiological differentiation is impossible. It is most important for radiologists to accept this premise and to appeal to the endo- N scopist for confirmation of the diagnosis (Figs. Io and I2).

In early cases of carcinoma, the diaphragmatic $\stackrel{N}{0}$ portion of the oesophagus may be narrowed and $\omega$ there may be a transient hold-up of fluid barium. $\frac{}{7}$ The mucosa will show some irregularity, however $\vec{a}$ slight, and the stenotic portion lacks the smooth, beak-like filling which characterizes cardiospasm. Careful examination of the gastric wall adjacent the cardia may show some irregular thickening. the growth extends towards the fundus, it can recognized by the increase in the soft tiss shadow between the diaphragm and the gastric $\frac{\bar{O}}{0}$ mucosa. If it extends below the cardia, the lesser curvature becomes irregular. An air bubble in $\stackrel{\mathbb{\Omega}}{\Omega}$ the fundus is found more commonly in carcinoma, $\overrightarrow{\vec{\partial}}$ and assists in examination of the mucosa.

A small sign which may be useful is the increase in wall rigidity just above the stenosis. The changes in contour with respiration show less flexibility than in achalasia and there is not the 3 . same tendency for the wall to bulge over the stenosis.

Irregular filling defects at the stenosis are $\delta$ characteristic of carcinoma, but their absence can $₹$ often be explained by the tendency for a number응 of these tumours to infiltrate interstitially. Re- $>$ tained food, unless acutely impacted in the stenosis, should not cause difficulty as the barium emulsion, sinking quickly to the bottom of the sac, displaces the other contents.

Thickening of the wall of the oesophagus does $N$ occur in carcinoma but it is not so marked. Slighto movement from cardiac pulsation may blur the margins in the $\mathrm{X}$-ray, producing an appearance of muscle hypertrophy.

Simple stricture. A common site for a simple stricture is from 2 to 3 in. above the diaphragm. There is usually a history of drinking a corrosive. 


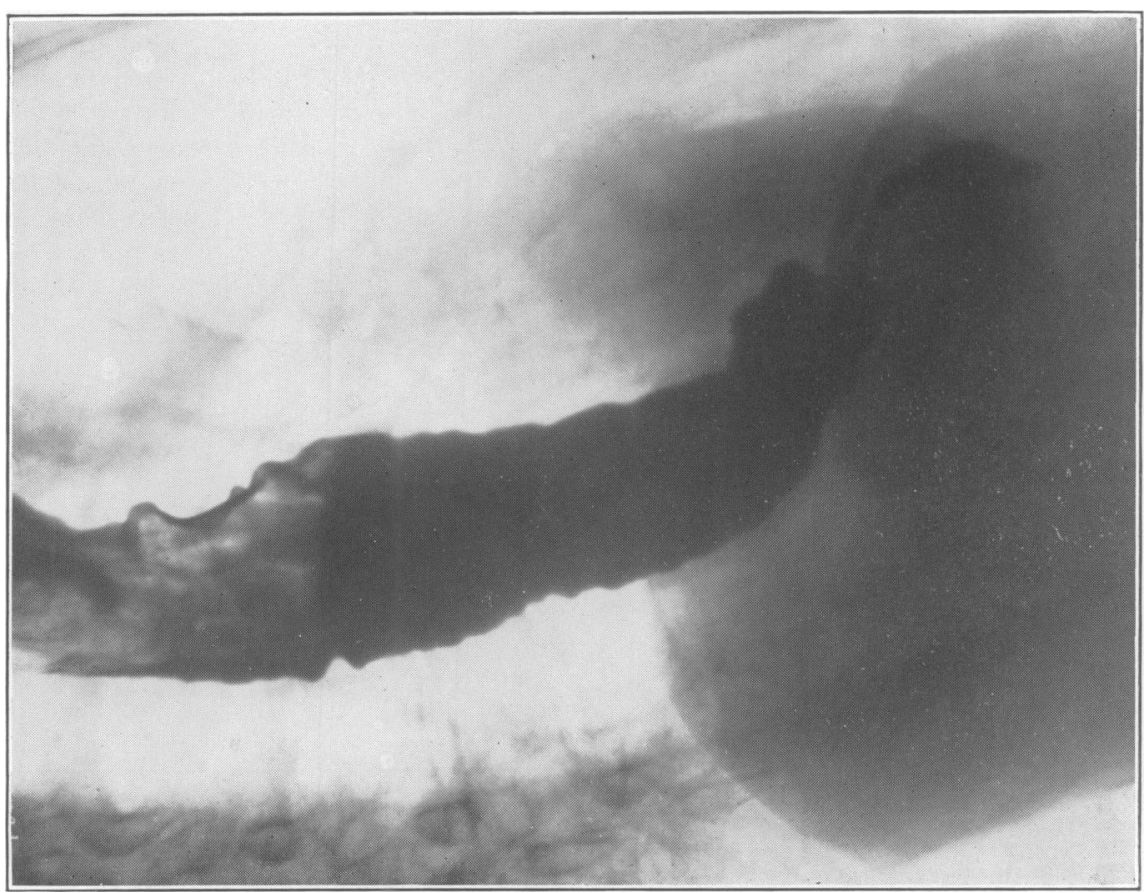



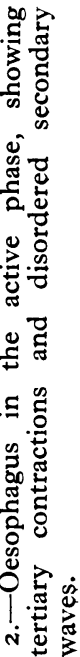

它

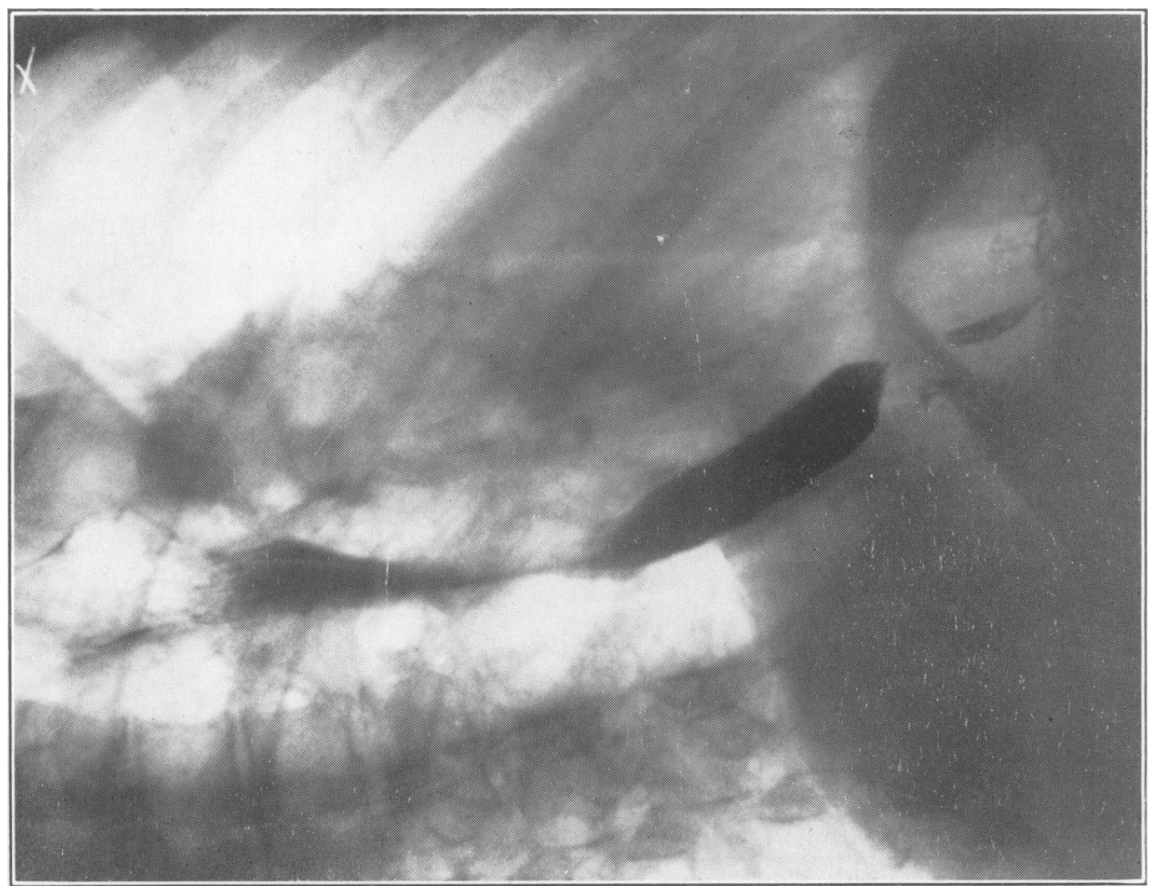

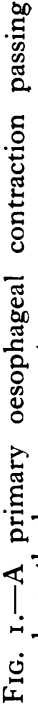

Dٓ

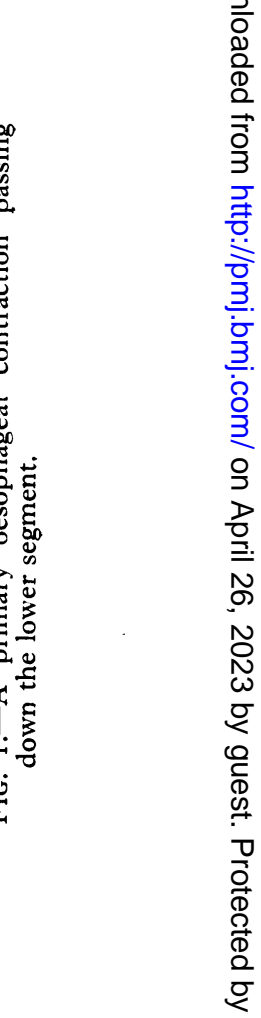




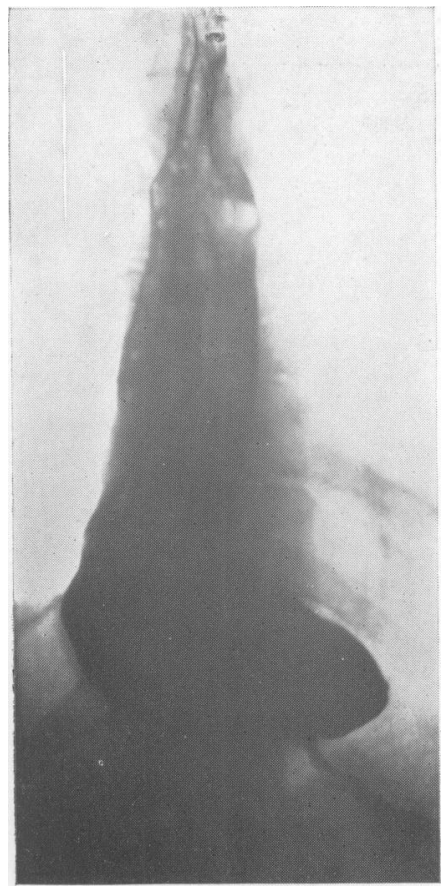

FIG. 3.-Oesophagus in the passive phase. Movements gradually cease. It becomes a tortuous, patulous bag.

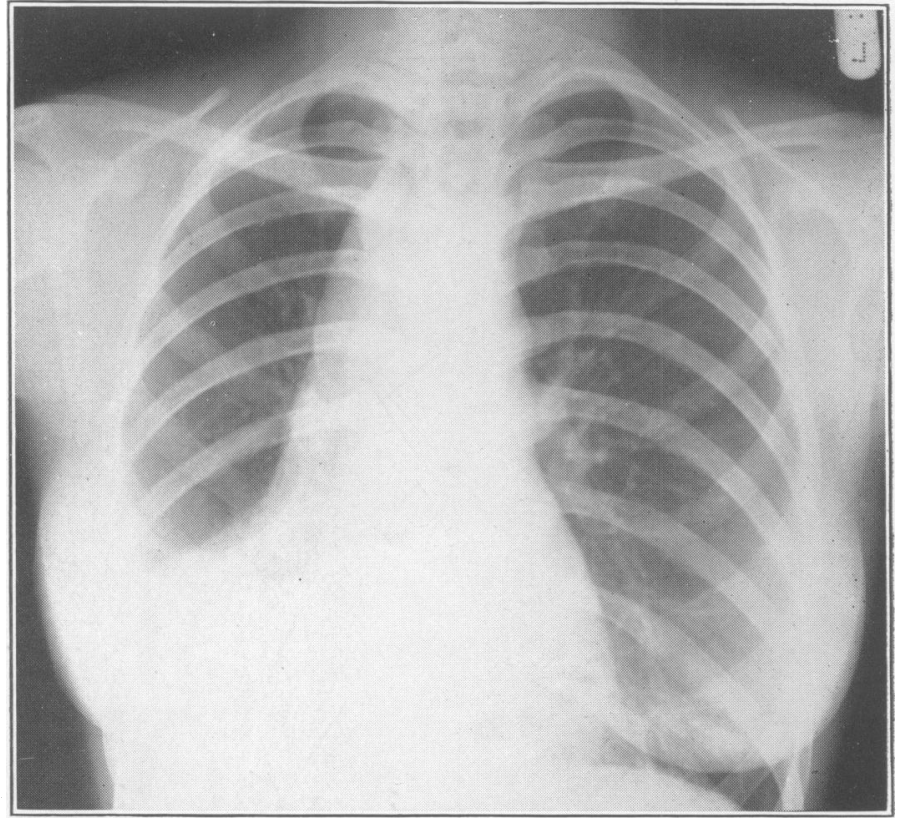

Fig. 4.- Lung complications. I. Atelectasis. The radiograph shows widening of the superior mediastinum due to the dilated oesophagus, and collapse of the right lower lobe. The latter reexpanded within 24 hours of the cardia being dilated with the Negus hydrostatic dilator.

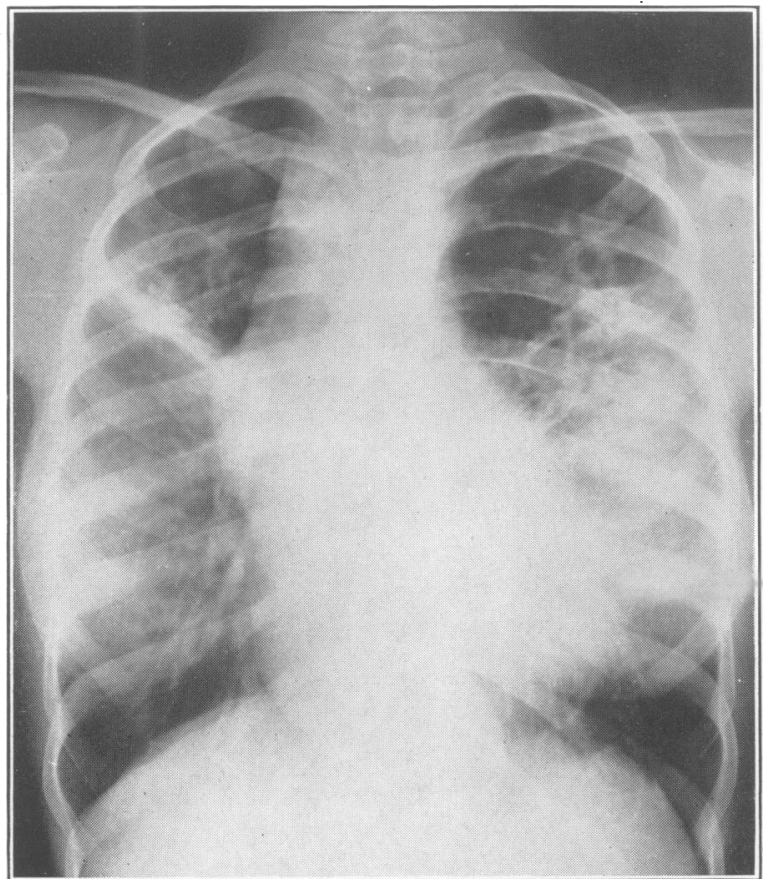

Fig. 5.-Lung complications. 2. Chronic inhalation pneumonia, or 'dysphagia pneumonitis,' causing bilateral fibrosis and bronchiectasis. 


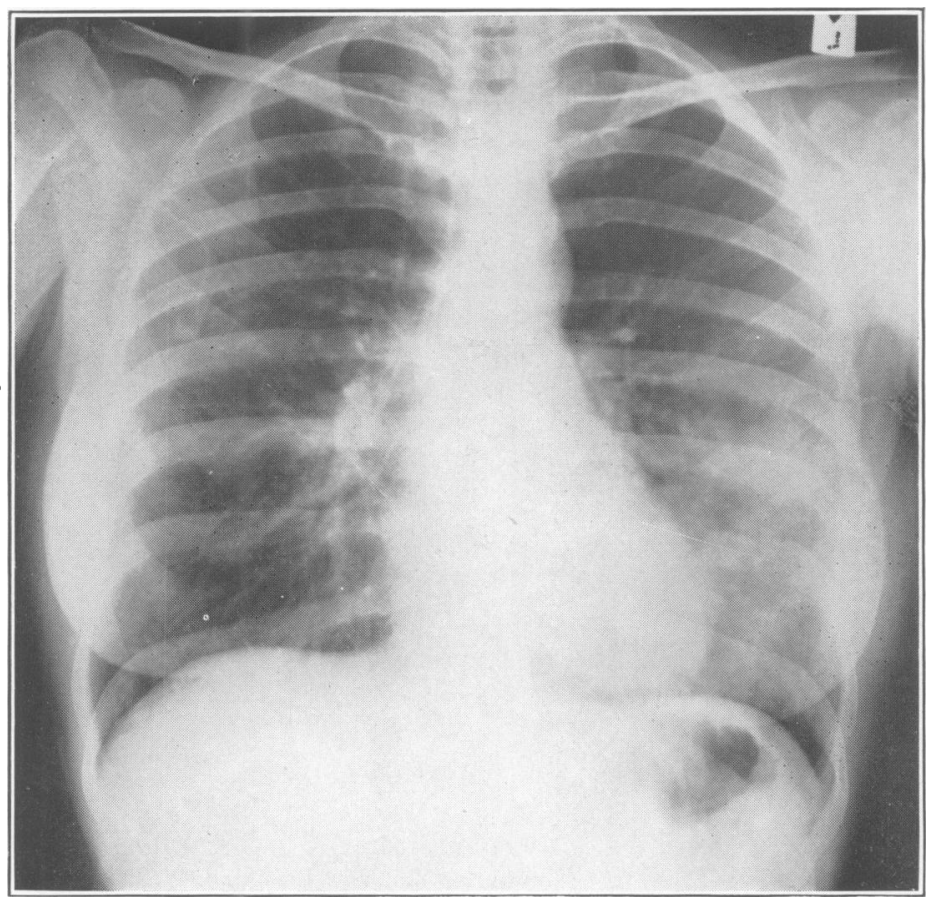

FIg. 6.-Lung complications. 3. Paraffin prieumonia, occurring in a patient with cardiospasm.

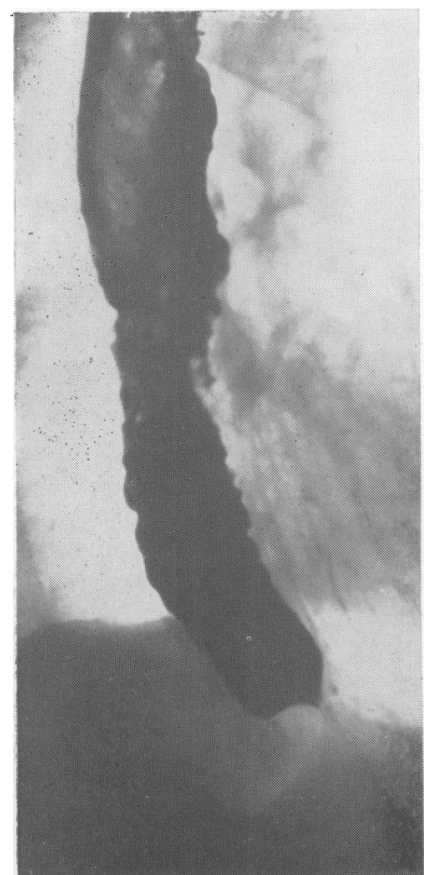

Fig. 7.-Cardiospasm in the active first stage showing the narrow diaphragmatic portion and many tertiary contractions in the lower segment of the oesophagus.

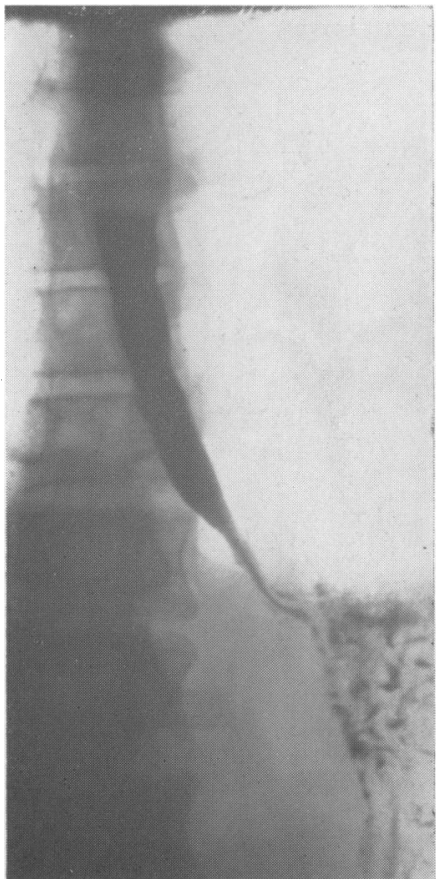

a

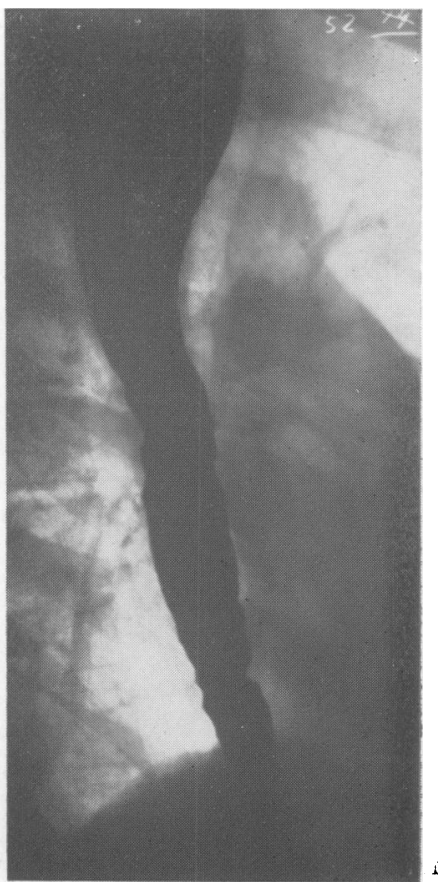

b
FIG. 8 ( $a$ and $b$ ).-An early case of cardiospasm. The upper, striped muscle segment shows the greatest dilatation. The lower plain muscle segment remains contracted and shows increased activity. 


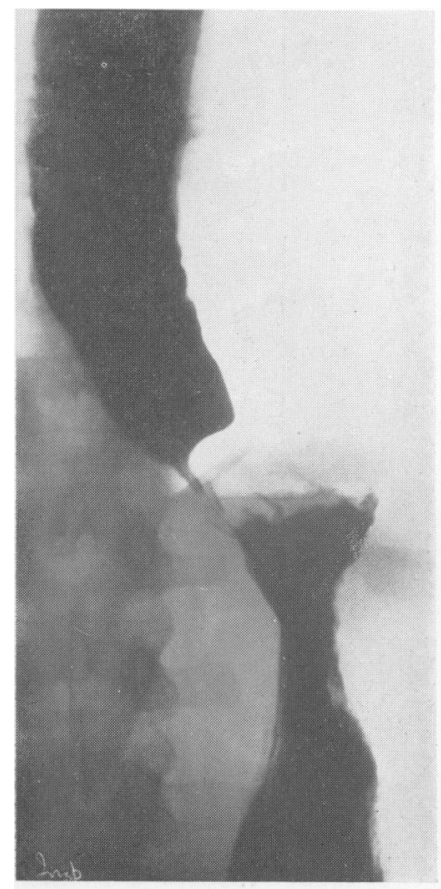

a

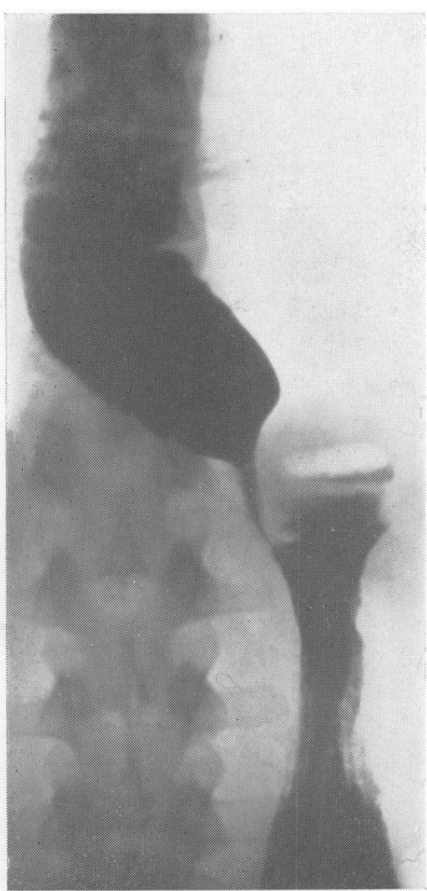

$\mathrm{b}$

FIG. 9.-To show the effect of respiration on the lower end of the oesophagus in cardiospasm. ( $\urcorner$ ) In inspiration. (b) In expiration.

FIG. 10.-Differential diagnosis from carcinoma of the cardia. Radiologically was thought to be cardiospasm. A tight stricture of the cardia was felt at oesophagoscopy; bleeding occurred. The patient had a diffuse infiltrating carcinoma of the stomach which was involving the cardia.

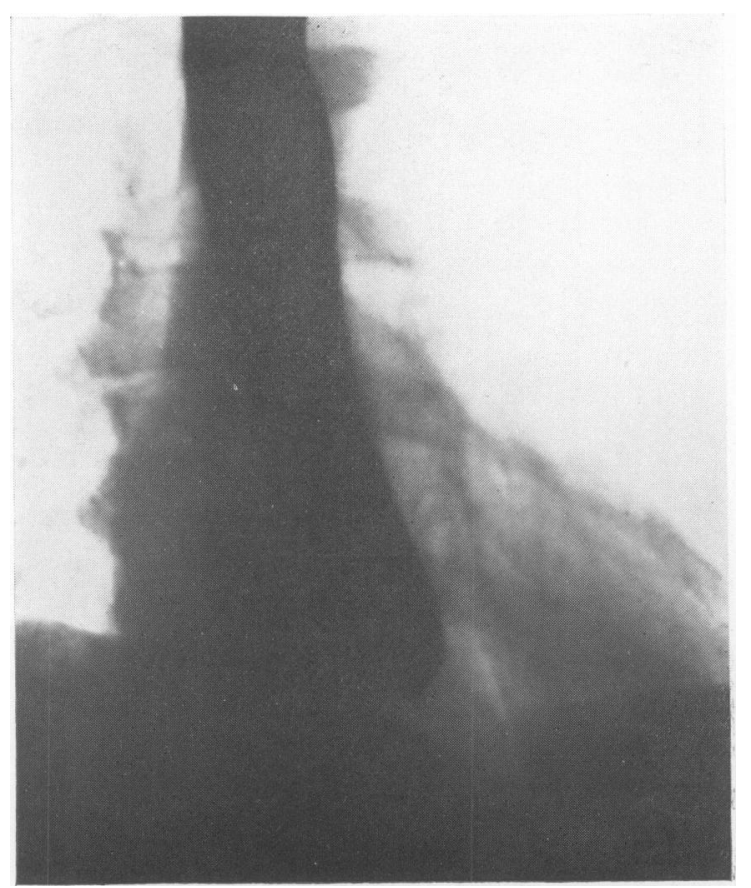




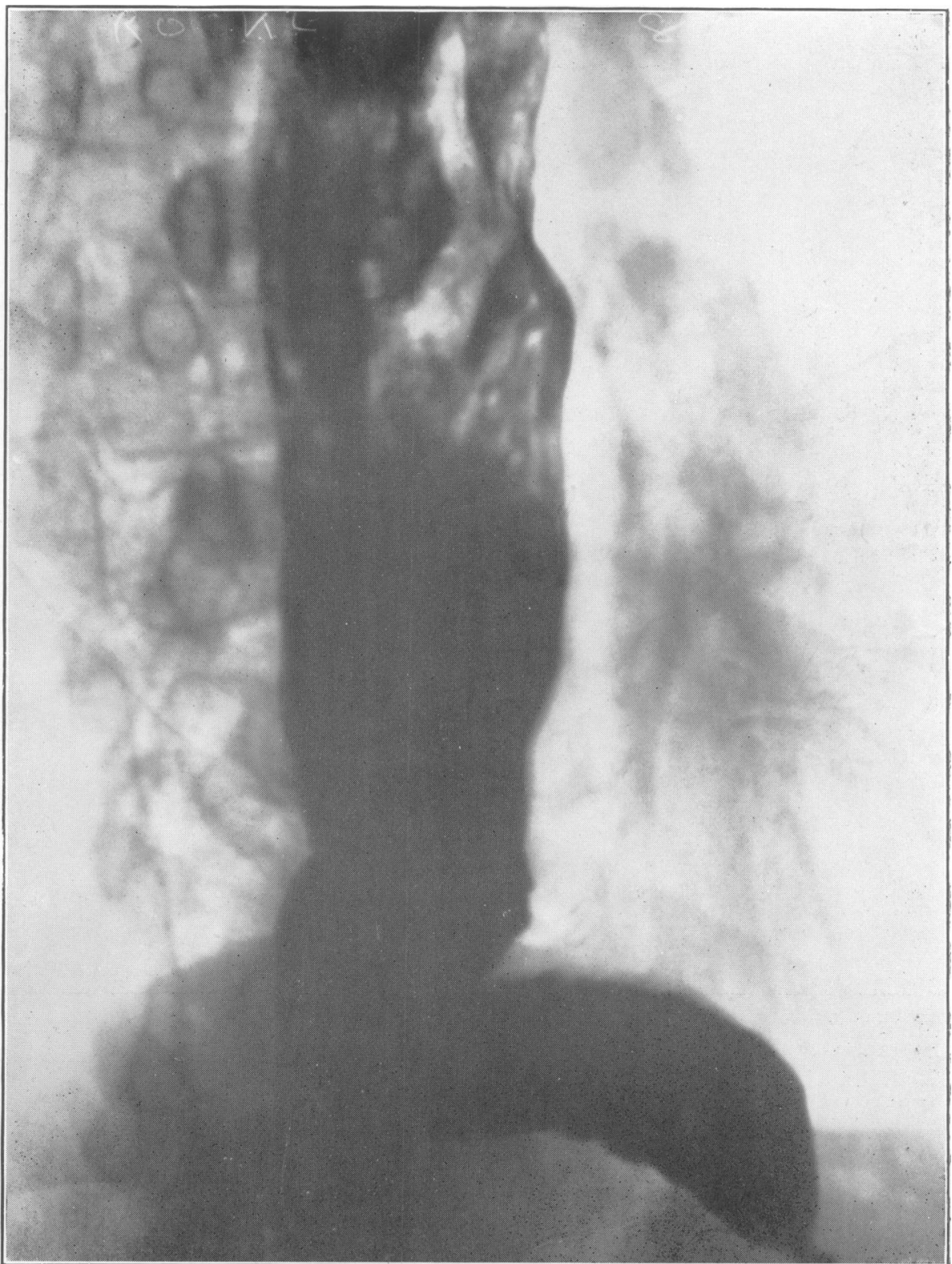

Fig. Ir.-The oesophagus is elongated and kinked. On oesophagoscopy the cardia may be difficult to find when it lies round a right angle bend to the left. 


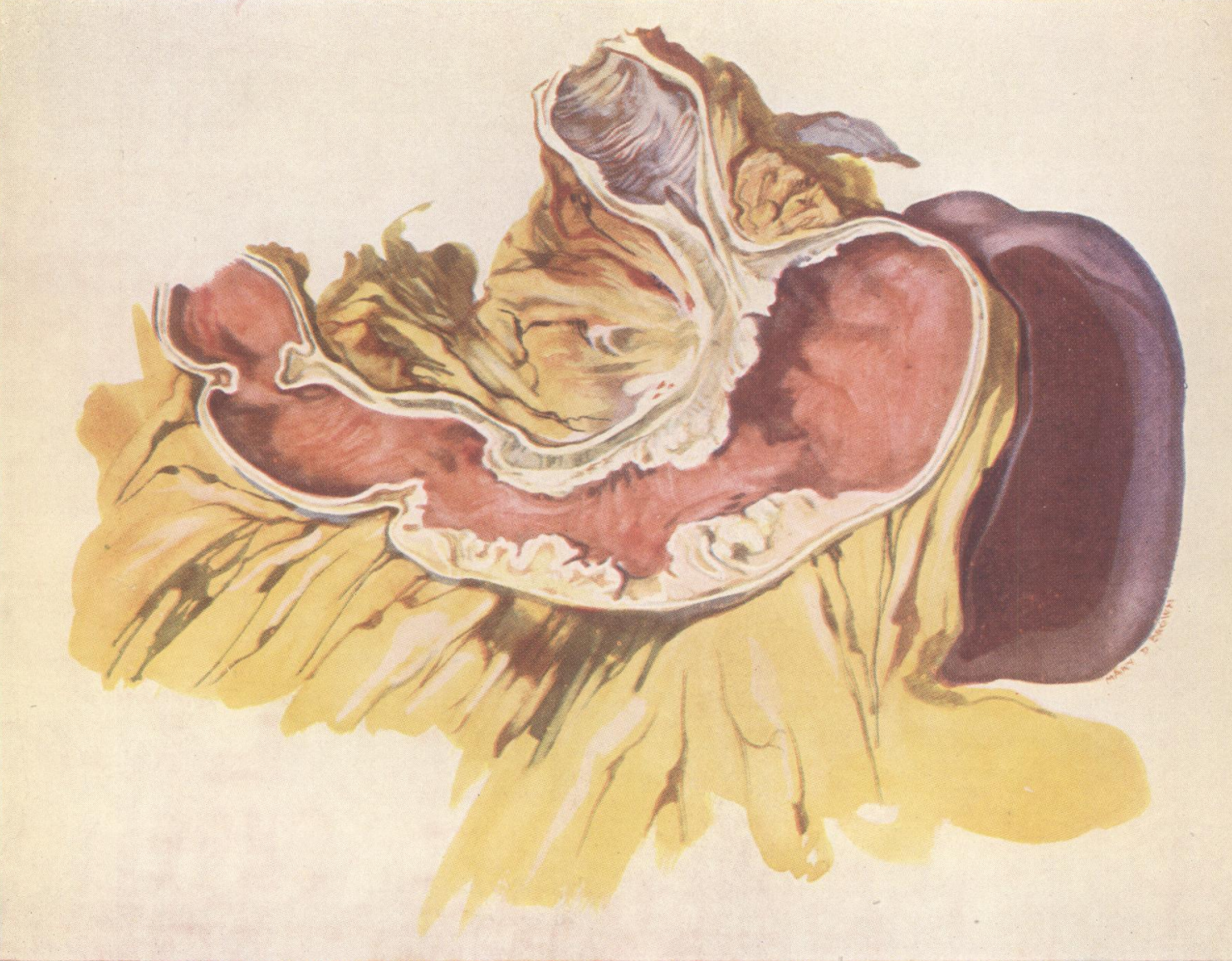

Fig. 12.-Differential diagnosis. Carcinoma of the stomach involving the cardia may easily be mistaken for cardiospasm. The specimen removed at operation from the same case as Fig. II. 
The walls are smooth, but may be hypertrophied, and peristalsis is normal. Dilatation does not become so marked except in acute obstruction.

Peptic ulceration. The site is usually 2 or 3 in. above the diaphragm. An ulcer crater may fill, showing a niche. If sufficient barium passes into the stomach, the demonstration of a hiatus hernia, which is almost inevitably present, will make the diagnosis.

Simple tumour. A tumour at the lower end of the oesophagus may cause such dilatation that it mimics a cardiospasm.

\section{Treatment of Cardiospasm}

The aetiology of cardiospasm remains unknown. No satisfactory operation has yet been devised on the nerve mechanism controlling the cardia to overcome the spasm. 'Repeated dilatations by means of oesophageal bougies or a mercury tube are distressing to the patient. Introduced in the I $7^{\text {th }}$ century, these methods have, however, enabled many patients to live in moderate comfort. More satisfactory forms of treatment are rupture of the muscle fibres by stretching and surgical division of the muscle in the constricted area.

In 1904, von Mikulicz described his operation of digital dilatation of the cardia through the stomach. Walton acclaims this method, but in our experience as good results are obtainable with the Negus hydrostatic dilator. The use of this instrument causes far less trouble to the patient. The treatment can be performed on out-patients and, if necessary, can easily be repeated.

The technique of using this dilator is as follows. The oesophagoscope is passed under general anaesthesia. After cleansing the oesophagus, the cardia is sought. This is dilated with gum elastic bougies up to size 30 . The stilette of the dilator is then passed through the cardia, and the Negus hydrostatic dilator is inserted over the stilette. It is important that the constricted part of the oesophagus should be in the centre of the Negus bag when the latter is distended by injecting $20-40 \mathrm{cc}$. of water. Otherwise the bag slips up or down, thus failing to dilate the constriction. It is difficult, however, to be certain that the bag lies in the centre of the constriction. In order that the dilatation shall be complete, the bag should be distended three or more times at varying distances from the incisor teeth. This method of dilatation is repeated twice at fortnightly intervals.

\section{Results of Treatment with the Negus Hydrostatic Dilator}

Out of a total of $6 \mathrm{r}$ cases, 46 received treatment with the Negus hydrostatic dilator. Eight of these were not successful and later required Heller's operation. The remaining 38 have been seen again up to a period of four years following treatment. Thirty-five can eat anything and state they have been cured, whilst the remaining three have been relieved to a certain extent. They are under observation because they are still having discomfort after food. Lack of response to the Negus dilator is due to failure to disrupt the muscle fibres.

When this method of dilatation has been given a fair trial and has proved unsuccessful, surgery is indicated. We believe that the best operation is an extra-mucous oesophago-cardiomyotomy first described by Heller in 19r3. The operation is described elsewhere in this number. It has given excellent results in the 16 patients upon whom it was performed in this series.

TABLE I

Summary of Treatment

\begin{tabular}{|c|c|c|}
\hline Total number of cases & 61 & \\
\hline I. Negus Dilator & $\begin{array}{r}46 \\
35 \\
8 \\
3\end{array}$ & $\begin{array}{l}\text { Good results. } \\
\text { Required Heller's } \\
\text { operation. } \\
\text { Still under observa- } \\
\text { tion. }\end{array}$ \\
\hline 2. Heller's operation. . & 16 & All good results. \\
\hline $\begin{array}{c}\text { 3. Mickulicz's opera- } \\
\text { tion }\end{array}$ & $\begin{array}{l}5 \\
3 \\
2\end{array}$ & $\begin{array}{l}\text { Good results. } \\
\text { Symptoms returned } \\
\text { and were relieved } \\
\text { with Negus Dilator. }\end{array}$ \\
\hline 4. Refused treatment & 2 & \\
\hline
\end{tabular}

It is therefore recommended that treatment should consist firstly of dilatation with the Negus hydrostatic dilator. If this fails, extra-mucous oesophago-cardiomyotomy has given excellent results.

\section{ACKNOWLEDGMENTS}

Our thanks are due to Mr. Philip Allison for his advice and for allowing us to publish these cases, most of whom have been treated by him. We should also like to thank Miss M. Brown for her painting of the specimen reproduced as Fig. 12.

Figs. I, 2, 4, 5, 6 and I I have been previously published in Thorax (1948, 3, 57, et seq.). They are reproduced by the courtesy of the Editors to whom our thanks are due.

\section{BIBLIOGRAPHY}

ALlison, P. R., JOHNSTONE, A. S., and ROYCE, C. B. (1943), fourn. Thoracic Surg., 12, 432.

ALVAREZ, W. C. (1939), 'An Introduction to Gastro-Enterology,' Heinemann, London. 
BARLOW, D. (1942), Brit. Fourn. Surg. , 29, 415.

BELCHER, J. R. (1949), Thorax, Vol. 4, I, 44.

BROWN, KELLY, A. (1919), fourn. Laryng. and Otol., 34, 289.

BRUCKE, E. T. VON, and SATAKE, J. (1913), Arch. ges. Physiol., r50, 208.

CARLSON, quoted by TEMPLETON.

DICK, R. C. S., and HURST, A. F. (1942), Quart. fourn. Med., II, 105 .

EINHORN, MAX (1888), Med. Rec., 34, 75 I.

FINDLAY, L. (r933), 'Thomson's Clinical Study and Treatment of Sick Children,' Oliver and Boyd.

FINDLAY, L., and KELLY, A. B. (I931), Fourn. Laryng. and Otol., 46, 797 .

GALLINARO, E. A. (1947), ' Rassegna di Neurologia Vegetative Estratto,' Vol. IV, No. 6, p. 464.

HACKER, V. VON, and LOTHEISSEN, G. (1926), 'Chirurgie der Speiserohne,' Stuttgart, Neue Deutsche Chirurgie, 34, 292.

HARRINGTON, S. W. (1943), Amer. Fourn. Roentg., xlix, 2, 185-196.

HELLER, E. (1913), Mitt. Grenzgeh. Med. Chir., 57, $14 \mathrm{I}$.

HELLER, E. (1921), Verhandl. dtsch. Gesellsch. Chir., 45, 144.

HURST, A. F. (1913), Proc. Roy. Soc. Med., Clin. Sect., 7, 150.

HURST, A. F. (1914), Proc. Roy. Soc. Med., Clin. Sect., 8, 22.

HURST, A. F. (1934), F. Amer. med. Ass., 102, 582.

JACKSON, CHEVALIER (1922), Laryngoscope, 32, 139.

JOHNSTONE, A. S. (1941), Brit. Yourn. Rad., xiv, 177.
JOHNSTONE, A. S. (1943), Brit. Fourn. Rad., xvi, 102, 357.

JOHNSTONE, A. S. (1946), Brit. fourn. Rad., xix, 219 , p. 101.

JOHNSTONE, A. S. (1946), Edin. Med. Fourn., 53, 160.

KNIGHT, G. C. (1934-35), Brit. Fourn. Surg., xxii, 155.

LAMBERT, A. V. S. (1913), Ann. Surg., 58, 415.

LENDRUM, F. C. (1937), Arch. Int. Med., 59, 475-93.

MAINGOT, R. (1944), Post-Grad. med. f., 20, 278.

MCLAREN, J. W. (1943), Brit. F. Radiol., 16, 270.

MIKULICZ, J. VON (1904), Dtsch. med. Wschr., 30, 17.

MOSHER, H. P. (1922), Laryngoscope, 32, 238.

OCHSNER and DE BAKEY (1940), Arch. Surg., 4r, 1146.

PATERSON, D. R. (1919), Fourn. Laryng. and Otol., 34, 285.

RAKE, G. W. (1926), Guy's Hosp. Rep., 76, 145.

RAKE, G. W. (1927), Guy's Hosp. Rep., 77, 141 .

ROLleSTON, H. (1896), Trans. Path. Soc. London, 47, 37.

SCHATZSKI, quoted by TEMPLETON.

TEMPLETON, F. E. (1944), 'X-Ray Examination of the Stomach,' Univ. Chicago Press.

TESCHENDORF, quoted by TEMPLETON.

VINSON, P. P. (1022), Minnesota Med., 5, 107.

WALDENSTROM and KJELLBERG (1939), Acta. Rad., $20,618$. WALTON, A. J. (1925), Brit. F. Surg., 12, 70r.

WILLIS, THOMAS (1672), 'Pharmaceutica Rationalis.'

WOOLER, G. H. (1948), Thorax, Vol. 3, No. 2, p. 53.

\section{RUTHIN CASTLE, NORTH WALES}

A Clinic for the diagnosis and treatment of Internal Diseases (except Mental or Infectious Diseases). The

Clinic is provided with a staff of doctors, technicians and nurses.

The surroundings are beautiful. The climate is mild. There is central heating throughout. The annual rainfall is 30.5 inches, that is, less than the average for England.

The Fees are inclusive and vary according to the room occupied.

For particulars apply to THE SECRETARY, Ruthin Castle, North Wales.

Telagrams : Castle, Ruthin.

Telephone : Ruthin 66 